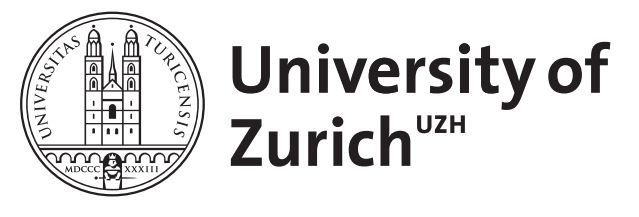

\title{
Tourist Office Counselling Service
}

\author{
Schmidt-Rauch, Susanne ; Fux, Michael ; Schwabe, Gerhard
}

\begin{abstract}
In an ongoing $\mathrm{R} \mathrm{D}$ project, the authors investigate the consultation situations of travel counselling in travel agencies and tourist offices at destinations. The first investigations described in this paper indicate more similarities than differences between these two situations. The design requirements for collaborative co-located travel counselling from previous work describe a reformulation of the consultation situation to a joint problem-solving one. Since this procedure was confirmed and the requirements development for tourist offices revealed similar needs, the authors decided to implement design requirements of co-located travel counselling to a prototype system for supporting a collaborative tourist office counselling situation. Initial results of a first proof-of-concept field study look promising for further work in this direction, as they enrich the situation with further problem-solving capabilities to the advantage of both customers and tourist office personnel.
\end{abstract}

Posted at the Zurich Open Repository and Archive, University of Zurich

ZORA URL: https://doi.org/10.5167/uzh-60522

Conference or Workshop Item

Accepted Version

Originally published at:

Schmidt-Rauch, Susanne; Fux, Michael; Schwabe, Gerhard (2011). Tourist Office Counselling Service. In: Information and Communication Technologies in Tourism 2011, Innsbruck, Austria, 1 January 2011. Springer, 391-402. 


\title{
Tourist Office Counselling Service
}

\author{
Susanne Schmidt-Rauch ${ }^{\mathrm{a}}$ \\ Michael Fux ${ }^{\mathrm{b}}$, and \\ Gerhard Schwabe \\ ${ }^{\text {a } U n i v e r s i t y ~ o f ~ Z u r i c h, ~ S w i t z e r l a n d ~}$ \\ [schmidt, schwabe]@ifi.uzh.ch \\ ${ }^{\mathrm{b}}$ University of Applied Sciences, Western Switzerland \\ michael.fux@hevs.ch
}

\begin{abstract}
In an ongoing $\mathrm{R} \& \mathrm{D}$ project, the authors investigate the consultation situations of travel counselling in travel agencies and tourist offices at destinations. The first investigations described in this paper indicate more similarities than differences between these two situations. The design requirements for collaborative co-located travel counselling from previous work describe a reformulation of the consultation situation to a joint problem-solving one. Since this procedure was confirmed and the requirements development for tourist offices revealed similar needs, the authors decided to implement design requirements of co-located travel counselling to a prototype system for supporting a collaborative tourist office counselling situation. Initial results of a first proof-of-concept field study look promising for further work in this direction, as they enrich the situation with further problem-solving capabilities to the advantage of both customers and tourist office personnel.
\end{abstract}

Keywords: collaborative counselling, destination counselling, traveller needs.

\section{Introduction and Background}

In an on-going $\mathrm{R} \& \mathrm{D}$ project, the authors aim to develop concepts for innovative ITsupported counselling services for travel and tourism (e.g., Novak \& Schwabe 2008). These services enable intermediaries to reconfigure their business models to successfully compete against pure Internet-based competitors. We thereby focus on the situation of the service encounter at the locus of a travel agency or a tourist office at the destination. Compared to the wide-spread opinion that the Internet will replace human-based counselling, the authors are convinced that travel agencies, as well as tourist offices, benefit from viewing the Internet as an opportunity of change. Thereby, integration of the advantages of interactive multimedia technologies, touchsensitive displays, and Web 2.0-technologies to a novel, but still personal, customeragent interaction, will provide new value-added counselling service. The counsellingrelated problem areas of the (1) principle-agent conflict, (2) the stickiness of information needs, and (3) the burden of choice motivate the overall situation reformulation to a joint problem-solving process in preference to a pure sales process. 
Regarding the problem area of the obvious (1) principal-agent conflict (e.g., Novak 2009), there are a number of potential pitfalls in a counselling situation that impair the interaction between the customer and agent. Since the agent usually sits behind a desk with access to several information sources and the customer has only access to the information the agent wants to provide, the customer has an information disadvantage. In other words, the customer cannot be sure that the agent acts in the customer's interest, and has no control about the situation that can decrease trust or foster distrust. This subsequently impairs counselling satisfaction, which can also negatively influence the customer's willingness to visit the travel agency or tourist office in order to purchase products. Beyond the privileged access to information, agents also possess the solution space that is hidden to the customer. Customers, on the other hand, enter an agency or tourist office with their own problem space in mind and have only a vague idea of the possible solutions. The task of the dialogue between the two actors then is to bridge the gap between the problem space and the solution space. This gap, however, can be difficult to bridge, depending on the travel needs of customers and their ability to communicate these information needs. Customers are commonly not able to explicitly describe their needs and desires, and have difficulty expressing these needs/desires in terms suitable to being directly mapped onto product offers (Schwabe et al. 2008, Novak \& Schwabe 2009). Transferring this "sticky" information (2) (Hippel \& Katz, 2002) to the agent is difficult and time consuming, and thus calls for a sophisticated dialogue in a travel agency or tourist office, or a high level of media competence during self-service via the Internet. Internet information, as well as the offerings at travel agencies or tourist offices, is almost unlimited. Decision-making becomes even more difficult with the exploration of new opportunities. Internet information additionally is accompanied with opinions, and customers have to decide whether they believe the information source or not, and need to come to a solution regarding their problem. These subsequent procedures can again be time-consuming and lead to cognitive overload described as (3) "burden of choice" (Schwartz 2005).

Apart from the essential travel information, feelings of pleasure and excitement are important information attendants (Goossens, 2000). Travel planning, as a process of generating a highly individualized travel product, is naturally a strong emotional process (Hyde, 1999). The product itself is thus attached to many feelings and emotional expectations that should be experienced right at the beginning of travel planning. This fact is already acknowledged in strategies and marketing efforts. The current authors' partner travel agency, for instance, follows a strategy for its counselling process labelled "Complete Experience" and defines counselling as a similar-to-trip experience. The authors' partner tourist office encounters its customers as "Echt" (meaning: authentic or credible) and labels websites, as well as flyers and brochures, with a short sentence according to the characteristic of the presented content (e.g., "Echt informativ"). This again emphasizes the form of service encounter: real attention to customers and their needs. The transfer to the counselling situation, however, is not yet existent. Although the awareness of providing an involving, enjoyable service encounter seems to be available not only by our partners (e.g., Globetrotter promises that their counselling is "more authentic, more 
informative, more profound" ${ }^{1}$, and Switzerland Tourism's marketing message is: "We do whatever it takes to make your holiday perfect." ${ }^{2}$ ), they do not differ explicitly from competitors regarding service. Suggested solutions to this gap between marketing and practice are interoperability, personalization, and constant networking (Buhalis and Law, 2008), as well as strategies for acting as online intermediaries (Buhalis and Licata, 2003). While innovative business models that see the Internet as an opportunity (Buhalis and Law, 2008; Barnett and Standing, 2001) have already been considered, these considerations only emphasize the online distribution channel (e.g., Fesenmaier et al., 2003). Offline distribution, as well as human advice, is neglected. Even insular attempts, such as the work of Hruschka and Mazanec (1990) that proposes an increased technical support of the agency's personnel, neglect the conceptualization of the human-human conversation and its interplay with the system, which is typically needed when designing a socio-technical system.

This paper follows a user-centred design process (ISO 1999). First, the investigations of the current situation in tourist offices are described. Second, the elaborated design requirements are presented according to the concept of collaborative travel counselling (Novak \& Schwabe 2009) with respect to the context of tourist offices. Subsequently, the system instantiation, SmartStay, is depicted, and an initial field study discussion follows. The paper ends with conclusions and future directions for this work.

\section{State of Practice in Tourist Offices}

In order to investigate the current work practice at tourist offices, a one-day-long qualitative observation at a tourist office (not the partner tourist office) was performed. Insights were used to arrange problem scenarios (Rosson \& Carroll 2003, p.64 et seq.) of current practice (concrete narrative stories) that had been validated with the general manager of the partner tourist office. Afterwards, interviews with four tourist office employees were conducted, and the service encounters at the partner tourist office during a high-traffic day were observed. Subsequently, insights were validated in two group discussions: first with the general manager and the sales manager, and then with the previously interviewed tourist office employees. The results of these investigations described in the following subsections can be organised according to four categories: environmental issues and the above introduced three counselling-related problem areas.

\subsection{Environmental Issues}

Environmental issues in this paper address the circumstances of tourist office counselling. Since most counselling aspects are linked to information access, organisational information gathering, and understanding the personnel, the environmental topics centre on the available knowledge and learning.

\footnotetext{
${ }^{1}$ Globetrotter's mission statement at globetrotter.ch [2010-09-16]

${ }^{2}$ myswitzerland.com [2010-09-16]
} 
Tourist office employees differ in knowledge regarding the destination and the offerings for tourists at the destination. Their fluency in counselling situations and competence that they are able to communicate to their guests depend on their personal experience of the destination. This problem of different service capabilities through knowledge differences grows with elevated fluctuation, which results in employees' repeatedly "forgetting" the organisational demand of selling products (such as hiking maps) - beyond pure counselling. While the organisation aims to sell products, employees aim to learn destination characteristics first, since these are a pre-condition for, e.g., map selling. Customers thus receive competent counselling only by accident.

In the situation of a new offering to-be-learned, there is usually only one approach taken: An e-mail is sent by management to inform employees, who then use flyers and brochures to learn more. These flyers are also intended to support counselling, and therefore being ahead of the knowledge of a guest is an illusion. Additionally, when tourist office employees need to search for information about other destinations, (offline) information often is out of date, or it is accessed through the website of the other destination. This can be time-consuming to the degree to which the website and destination are unknown. Consequently, the service encounter will last longer since this research takes place during counselling and the guest potentially becomes frustrated. This knowledge development problem even grows due to the missing organisational embedding of learning-on-the-job time as well as an appropriate program.

\subsection{Information-Asymmetry Issues}

When guests enter a tourist office and ask for assistance regarding accommodation, they ask infrastructural questions (e.g., "where is X", "what does location Y look like?"), or they request activities counselling. Concerning accommodation counselling, the tourist office employee searches for available hotels using the local databases and digital transaction interfaces. Information is searched and filtered first by the employee, and the customer is involved only when the employee decides to involve him or her. The customer's boredom while the employee uses the PC is visible in his or her behaviour: looking out of a window or by an unmotivatedthumbing-through a brochure. Active guests manifest this potential for distrust by trying to have a look at the screen by leaning uncomfortably over the desk. When the employee is ready, s/he shows the hotel pictures on the small screen, turned to the guest. After a decision is made, a location is depicted on a physical (cost-free) destination map. This reflects the information asymmetry that, in most cases, results in staccato counselling - switching between different media and material. With this frustration, the situation is prone to confuse the guest and lead to his/her distrust of the employee ("What does the tourist office employee do during the silent time slot of his/her search using the PC?").

\subsection{Burden-of-Choice Issues}

The guests' impatience during the silent time slots depicts another important issue of tourist office service encounters: time pressure. A service encounter typically lasts 
around five minutes but can also be even shorter, e.g., when a guest only asks for a bus schedule. Tourist office employees are advised to efficiently conduct advicegiving when guests expect a short destination counselling. Most observed guests enter the tourist offices ready to experience their activity (e.g., wearing hiking boots), which leads to the employee's impression that the guests expect the counselling to be short. With an increasing number of guests, employees tend to shorten encounters even more. They do this by referring to printed material, which guests sometimes even have to take themselves from a shelf. The guest's recognition of this can be observed by his/her refusal of self-informing expressed in slight anger. Tourist office employees confirm our observation by stating: "Guests refuse reading on their own. They want the right information quickly and from me." Summing this up, the basic need for individual service aimed at personalized solutions (products) is undermined by that behaviour.

Following the afore-mentioned need for external material to efficiently shorten encounters, a tourist office's task is to provide personal information and prepare selfservice information (usually by catalogues, brochures, flyers, etc.). In any case, the organisation needs to integrate as much information as possible from a great number of service and product providers to act with 'one face to the customer' ${ }^{3}$. This information integration problem exists in the offline and online world.

\subsection{Sticky-Information-Needs Issues}

As mentioned above, entering guests are implicitly segmented according to the three demand segments of accommodation counselling, infrastructural counselling, and activities counselling. This segmentation in itself produces a straight-forward counselling that, on the one hand, is quick and goal-oriented, but on the other hand, hinders inspiration and the possibility of hidden needs elicitation. Guests with less specific ideas of what they want to do will not receive satisfactory service. Thus, addressing the stickiness of information needs is violated.

Regarding the second demand of infrastructural counselling, guests feel a gap, for instance, between the description of a flyer (e.g., an ice pavilion) and their understanding (e.g., where the ice pavilion is located). Thus, 'creative' language is needed from the tourist office employee since s/he often just does not have access to more than the flyer. The same holds true for accommodation counselling when PC monitors are inaccessible, and pictures of a hotel or a hotel room are unavailable or of low quality. This visual expression deficiency leads to unsatisfactory service encounters which risk cancelling the counselling and potentially close sales opportunities (e.g., hotel bookings, map selling).

In terms of activities counselling, we have to differentiate between summer and winter (in this case, an alpine destination). Guests in winter visit the Alps to enjoy sports such as skiing. The relevant product variety may be rather limited, while the

\footnotetext{
3 'One face to the customer' is a soundbite summing up the idea to provide customers with service from one source to improve customer interaction (Fiorina, 2002).
} 
guests' demand can be very specific. Contrarily, summer guests have greatly varying demands, especially for activities (requiring more than a ski pass) where the solution space is much larger than in winter. The specific counselling on activities (like a concert visit) is exacerbated through the unavailability of (multi-) medial presentation material, since from the tourist office's perspective, a flyer is not worthwhile printing due to the short time frame of the event. Since in summer the guests' main demands are focussed on hiking counselling and searching for appropriate maps, the destination already offers interactive maps of the region on the website; however, these maps are tailored to the needs of mountain railways, and may contain some useless information (e.g., state of open slopes), and also lack specific interesting information (e.g., an alpine garden). Hence, these maps are inappropriate for guests who are interested in more than just the mountain railway. The problem of improper material is also noticeable regarding the huge number of different flyers which embody the general disadvantages of analogous information (not limited to the itemized): they do not grow old but become out-of-date. Further information can only be received by a modal fragmentation, and searching them is linear. Guests regard these disadvantages as an unsatisfactory vacation interruption, and leave the tourist office no wiser than before, reflected in their looks of frustration.

\section{Design Requirements for Collaborative Destination Counselling}

The current work practice can be summarized according to the problems depicted in Table 1. A transfer to specific design requirements (right column) is given according to the problem categories.

Table 1. Tourist office counselling problems (left) according to problem categories and requirements for an improved counselling (right)

Problem Statement (PS) in Destination Counselling
Design Requirements (DR) for Improved Destination Counselling

\section{information asymmetry}

PS1. Potential of distrust describes the occurrence of the principle-agent conflict in destination counselling

PS2. Staccato counselling issue describes the uncomfortable waiting times for the guest and his/her reduced involvement
DR1. Provide shared information access and DR2. shared interaction to stimulate involvement and foster empowerment of the guest in a continuous counselling with traceable actions

\begin{tabular}{|c|c|}
\hline \multicolumn{2}{|c|}{ burden of choice } \\
\hline $\begin{array}{l}\text { PS3. Time pressure describes the nature of } \\
\text { destination counselling sessions which typically } \\
\text { are rather short (approx. five minutes on average) }\end{array}$ & $\begin{array}{l}\text { DR3. Provide short cuts and fast } \\
\text { tracks to common demands }\end{array}$ \\
\hline $\begin{array}{l}\text { PS4. Information integration problem describes the } \\
\text { deluge of paperwork and the amount of Internet } \\
\text { resources needed for counselling }\end{array}$ & $\begin{array}{l}\text { DR4. Provide integrated forms of } \\
\text { information gathering for } \\
\text { comprehensive product impression }\end{array}$ \\
\hline
\end{tabular}


PS5. Missing hidden needs elicitation describes the absence of an inspiring counselling form and sufficient material

PS6. Visual expression deficiency depends on inadequate used or missing tools / material (is exacerbated by unavailable (multi-) medial presentation material and the problem of improper material)

\begin{tabular}{|c|c|}
\hline \multicolumn{2}{|l|}{ environment } \\
\hline $\begin{array}{l}\text { PS7. Knowledge development problem describes } \\
\text { the result of introducing new products and service } \\
\text { to an environment of a high employee turnover }\end{array}$ & $\begin{array}{l}\text { DR7. Provide maintenance } \\
\text { opportunities for content and } \\
\text { possibilities for quick-learn-paths }\end{array}$ \\
\hline $\begin{array}{l}\text { PS8. Problem of differing service capabilities } \\
\text { describes a result of a high employee turnover and } \\
\text { missing training-on-the-job concepts }\end{array}$ & $\begin{array}{l}\text { DR8. Provide an easy-to-learn } \\
\text { interface and increase content } \\
\text { accessibility to support learning }\end{array}$ \\
\hline
\end{tabular}

In a shared meeting consisting of the design team, software developers and general manager, as well as sales manager, DR1-DR6 were finally chosen for instantiation, since DR7 and DR8 are long-term design requirements, whose evaluation is only possible when DR1-DR6 are confirmed and are proven to be suitable.

\section{Instantiating Collaborative Destination Counselling}

A typical workflow of hiking counselling starts with a tourist (Beat), wearing, e.g., hiking shoes and entering the tourist office. A kind tourist office employee (Regula) welcomes him and invites him to have a look at the destination counselling support system, SmartStay (see Figure 1 for a screenshot), that is running on a 23" touchsensitive screen (DR6 since touch-sensitivity and screen size can positively influence emotional involvement (Novak \& Schmidt 2009)). Regula asks Beat how she can help him. Beat answers that he wants advice for a hiking tour, but it should be not that difficult. Regula briefly introduces the touch-functionality and suggests that together they can search for a most suitable tour. Since SmartStay allows directly searching for hiking tours, Regula clicks on the relevant button from the demand segments area (DR3, 4), and soon a map (Google Earth), as well as listed hiking tours, appear. Since Beat is noticeably in a hurry, Regula scrolls through the listed tours and suggests two easy and one gourmet hiking tour with a medium rating, which they decide to further investigate. Beat is interested in the tour details and is really intrigued by the gourmet hiking tour. He decides to save the gourmet hiking tour to his itinerary (DR1, 2). Since he also wants to stay independent, he asks whether there are additional places near the tour route to enjoy interesting food. Thereupon Regula opens the street-map on the screen and includes the restaurants layer. Pictures of restaurants appear in the column of additional offers which draw Beat's attention (DR5, 6). He asks for the special "crime and dine" offer, which Regula briefly explains and then adds to the itinerary. Finally, Beat asks for a map he would need. Regula suggests buying the local hiking map that also includes the other two hiking tours. When the itinerary with the chosen offers is printed and paid for, Beat happily leaves the tourist office. 


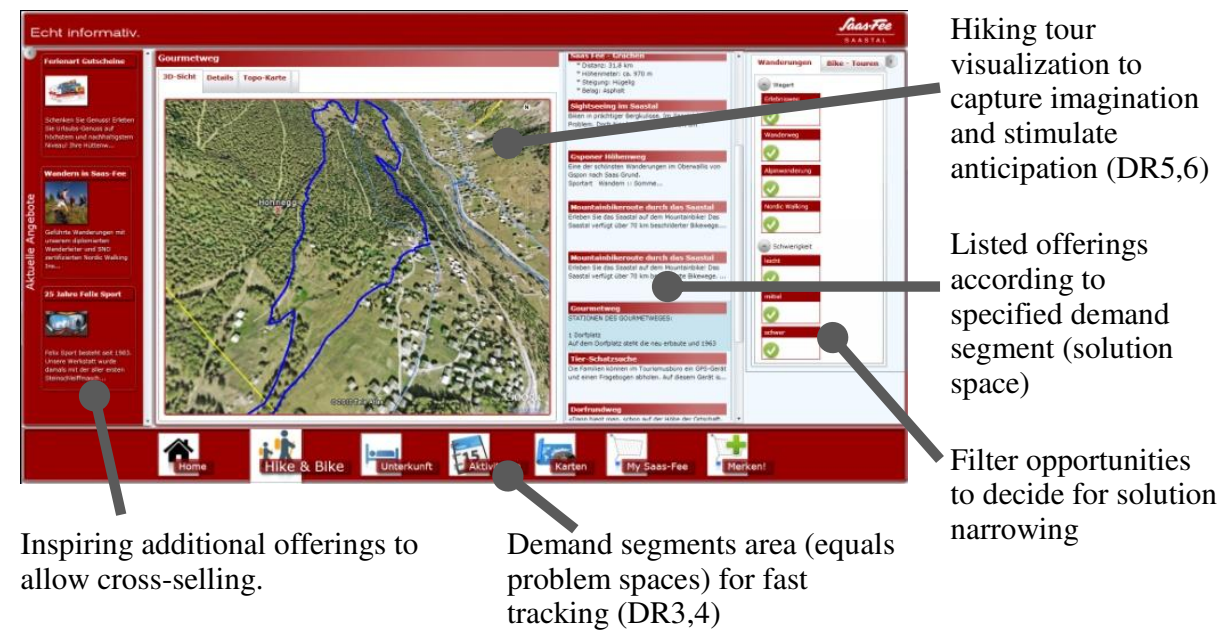

Figure 1. SmartStay prototype screenshot

The interaction with the tool, SmartStay, is very brief since the counselling in destination is only short-timed. Add-on time for the employee for first understanding the system feedback, translating it to the guest, and then visualizing it anywhere is reduced to a minimum. Guests find their demands directly on the screen, and they receive the needed visualization while they are in the search process. This enables both parties to be quickly well-informed.

\section{First Empirical Investigation}

On a one-day field study, the prototype system was set up at the partner tourist office including the touch-sensitive screen (see Figure 2). The within-subjects testing was combined with the following workshop-like debriefing on that day. Observation impressions were discussed during the debriefing. The study took place in winter and the prototype content was optimized to that case.

\subsection{Participants, tasks, setting}

Six tourist office employees, four appointed guests, as well as two spontaneous guests were involved. Employees were between 18 and 51 years of age, and guests ranged between 17 and 68. In a within-subjects design, guests and employees experienced either the traditional setting or the enhanced situation first, and the other one afterwards. The three counselling tasks were framed to the available content of the prototype system. The tasks were to plan a mountain hiking tour, an activity for kids during the next three days, and a search for a hotel room on short notice, including availability check. Guests were framed to the demand but were asked to behave as they usually would (regarding price, interest, etc.). Each task was performed twice during the study for both traditional and enhanced setting. Each session was limited to five minutes since this reflects the typical time span for counselling at the destination. After a guest had performed both settings, s/he was asked to fill out a questionnaire. 
Afterwards, an informal discussion about system and test experiences was held with each participating guest. Tourist office employees received a 30-minutes hands-on training of the system before the test start. After employees had finished their sessions, they were also asked to fill out a questionnaire, and were requested to join the debriefing after all test trials.

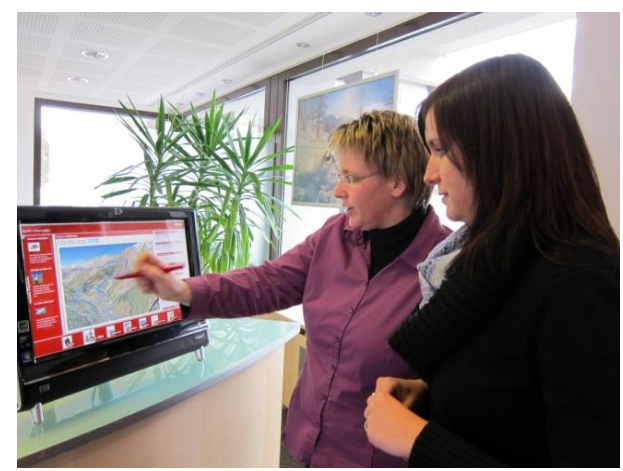

Figure 2. Tourist office employee (using a pen) explaining a map view on the touchsensitive screen (on the counter) to the customer

\subsection{Measurement}

The evaluation was operationalized according to design requirements. During observation concentration was placed on tendencies of joint problem-solving and the guest's activity (DR1, 2). Additionally, the guest, as well as the employee questionnaire, contained: the Attrakdiff2 semantic differential (Hassenzahl et al., 2003) for pragmatic (DR3, 4) and hedonic quality aspects (DR5, 6), direct questions regarding effectiveness (very good result) and efficiency (very fast achieved) of system use in the experienced context (DR3, 4), and a final intention-to-use judgment (adopted from (Venkatesh, 2003)).

The semantic differential of Attrakdiff2 (Hassenzahl et al., 2003) measures the overall user experience in the two dimensions of hedonic and pragmatic quality, which are proven to be distinguishable from each other by users. While pragmatic quality (PQ) reflects the usefulness and ease of use of a system, hedonic quality (HQ) reflects system qualities "beyond the instrumental" (Hassenzahl \& Tractinsky, 2006). These aspects address the ability of the system in use "to surprise, to foster curiosity and to provide opportunities for the perfection of knowledge and skills" (HQ-aspect of stimulation - HQ-S) (Hassenzahl, 2005), and the ability "to communicate self-serving symbols to relevant others" (HQ-aspect of identity - HQ-I) (Hassenzahl, 2005). Each quality aspect is constructed by seven items whereby the participant is asked to indicate on a seven-point Likert scale whether the destination counselling (traditional and again for enhanced) is, e.g., undemanding or challenging (as example for HQ-S), unprofessional or professional (as example for HQ-I), and confusing or clearly structured (as example for PQ). (We additionally paraphrased the PQ-dimension by direct questions on effectiveness and ease of use.) The final intention-to-use judgment (adopted from Venkatesh, 2003) provides a cautious glance at the potentials in the 
future of system and service acceptance. Ratings were conducted on a seven-point Likert scale and the following three items: (1) I intend to use the SmartStay-supported destination counselling for my next near-term planning at the destination, (2) I predict to use the SmartStay-supported destination counselling for my next near-term planning at the destination, and (3) I plan to only use SmartStay-supported destination counselling for my next near-term planning at the destination.

\subsection{Results}

Since the sample was constrained to only six guests and six tourist office employees, the data analysis was limited to average calculations, and the data was enhanced with the observation descriptions and debriefing results.

The results from the Attrakdiff2-instrument indicate a high advantage of the SmartStay-enhanced situation regarding stimulation quality ( $\varnothing 6.2$ vs. 3.6). Guests confirm this by lauding the integrated 3D maps with the tour visualizations with different perspectives and zoom levels. Observations revealed that especially the $3 \mathrm{D}$ maps were most often used (in all enhanced sessions), and all participants mentioned this feature as most valuable (e.g., "I was impressed by the maps"). Touching the screen additionally enhanced the impression ("Hu, I can touch my hiking tour"). One participant knew Google Earth and indicated a high satisfaction regarding that kind of destination counselling: "Finally it sunk in! This is a modern counselling." Regarding the identity aspect, participants had difficulty answering the questionnaire (e.g., "alienating" vs. "integrating" was difficult to interpret), which they indicated during the ticking of boxes. Although word pairs were then explained, ratings must not be as intended (enhanced: $\varnothing 5.8$ vs. traditional: $\varnothing 5.6$ ). The pragmatic quality is marginally lower for the enhanced situation ( $\varnothing 5.6$ vs. 5.7). Compared to the results of the paraphrasing, the picture about the system's utility is slightly different. Guests indicated a higher agreement to the statement "SmartStay-enhanced counselling led to a very good result" ( $\varnothing 6.1$ vs. 5.4), as well as to the statement "SmartStay-enhanced counselling led very fast to a result" ( $\varnothing 6.4$ vs. 5.9). When guests were asked about that discrepancy they indicated they were undecided about the utility of the two situations; thus, they rated the direct questions higher due to the joy they felt in the enhanced situation. Since they were not aware of the implications of the semantic differential rating, the effect of enjoyment outshining effectiveness and efficiency is not visible.

The intention to use SmartStay for destination counselling clearly shows a high interest in such counselling ( $\varnothing 5.4)$. Without the exclusive third item of that construct, SmartStay reaches an even higher rating ( $\varnothing 6.2$ ). The debriefing concerning this issue revealed that guests do not perceive the system inset as commonly useful. There were cases, for instance, of only asking for a certain address or bus schedule, whereby the system would be excessive.

Apart from the questionnaire-guided debriefing, the six framed traditional and six enhanced situations were also observed. During the traditional counselling sessions, the first observations that led to system design were confirmed. Additionally, while in 
traditional counselling, active and curious guests expressed their activity by leaning over the desk, as they were very interested in touching the map on their own in the enhanced situation. Commonly, there are very active guests in enhanced counselling clicking on buttons, moving and zooming maps, or discovering interesting offers that the tourist office employee had not noticed before. Guests experience this as increased involvement. All guests, on the other hand, criticized the still predominantly textheavy content. They agreed with tourist office employees that a second generation of the system needs to provide more context-oriented, multi-media content. They mentioned, for instance, short films for activities which could enrich the impression of activities. Tourist office employees were especially concerned about the furnishings and the integration of a possible technology with the shop concept.

\section{Conclusion and Future Directions}

Based on previous experiences in travel agencies, this paper presents a first step to collaborative destination counselling. The presented concept addresses the identified three problem areas of the principle-agent conflict, the burden of choice, and the stickiness of information needs, and thereby provides a perspective on destination counselling that focuses on actors and their interaction. Derived design requirements have been instantiated by SmartStay, which combines information and interaction sharing, burden-of-choice-reducing segmentation, and an imaginary, "touchable" content presentation accompanied by a touch-sensitive screen. The initial field study uncovered potential for improvement.

The equalizing situation is beneficial to both guests and employees. Since SmartStay is the first attempt, improvements and further development are needed. Contextawareness and text-reducing preparation of content are crucial due to time pressure. Therefore, the concept of demand segmentation appears to be not only useful but very necessary. Beyond system characteristics, an emphasized process support (needs elicitation, procedures while planning, alternatives comparison, etc.) needs to be considered for future service versions to foster sales orientation. A suitable counselling method needs to empower the guests while supporting the moderating role of the employee adequately. It needs to establish direct relations to cross- and upselling opportunities, and needs to address printed artefacts as "information outsourcing" (esp. regarding texts). A rethink of the workplace situation according to workplace ergonomics and work psychology is also needed. The described measurements for concentrating within the retrospective discussions build a baseline for future evaluations with larger sample sizes when a further developed version of SmartStay can be introduced to daily business.

For further embedding of the new service design, accompanying scenarios can be envisioned: a distributed counselling scenario which enables involving a tourist office employee of a neighbouring destination and a mobile scenario which enables taking along information digitally or using digital tickets for activities. 


\section{References}

Barnett, M. \& Standing, C. (2001). Repositioning travel agencies on the Internet. Journal of Vacation Marketing, 7, pp. 143-152.

Buhalis, D. \& Licata, M. C. (2002). The future eTourism intermediaries, Tourism Management, 23 (3), pp. 207-220.

Buhalis, D. \& Law, R. (2008). Progress in information technology and tourism management: 20 years on and 10 years after the Internet-The state of eTourism research, Tourism Management, 29 (4), pp. 609-623.

Dilts, J. \& Prough, G. (2002). Travel Agencies: A Service Industry in Transition in the Networked Economy, The Marketing Management Journal, 13 (2), pp. 96-106.

Fesenmaier, D., Ricci, F., Schaumlechner, E., Wober, K. \& Zanella, C. (2003). DIETORECS: Travel Counselling for Multiple Decision Styles, Proceedings of the ENTER 2003 Conference, Helsinki, Finland, pp. 232-242.

Fiorina, C. (2002). HP and Oracle: Allies for Customer Success. Speech at Oracle Appsworld, San Diego, California, April $8^{\text {th }}$, 2002, requested from http://www.hp.com/hpinfo /execteam/speeches/fiorina/oracleapps_02.html, [2010-11-01]

Goossens, C. (2000). Tourism Information and Pleasure Motivation, Annals of Tourism Research, 27 (2), pp. 301-321.

Hassenzahl, M., Burmester, M. \& Koller, F. (2003). Attrakdiff: Ein Fragebogen zur Messung wahrgenommener hedonischer und pragmatischer Qualität, Proc. Mensch \& Computer 2003, pp.187-196

Hassenzahl, M. (2005). The Thing and I: Understanding the Relationship Between User and Product, in: Blythe, M.A., Overbeeke, K., Monk, A.F. \& Wright, P.C. (Eds.), Funology - From Usability to Enjoyment, Springer, pp. 31-42.

Hassenzahl, M. \& Tractinsky, N. (2006). User experience - a research agenda, J. of Behaviour \& Information Technology, 25 (2), pp. 91-97.

von Hippel, E. \& Katz, R. (2002). Shifting Innovation to Users via Toolkits. Management Science, 48(7).

Hruschka, H. \& Mazanec, J. (1990). Computer-assisted travel counseling. Annals of Tourism Research, 14, pp. 208-227.

Hyde, K.F. (1999). A Hedonic Perspective on Independent Vacation Planning, DecisionMaking and Behaviour. Consumer Psychology of Tourism, Hospitality and Leisure, pp. 177-191.

International Organization for Standardization (1999). ISO 13407 - Human-centered design processes for interactive systems.

Novak, J. (2009). Mine, Yours...Ours? Designing for Principal-Agent Collaboration in Interactive Value Creation, Proc. of Wirtschaftsinformatik 2009, Vienna, Austria.

Novak, J. \& Schwabe, G. 2009. Designing for reintermediation in the brick-and-mortar world: Towards the travel agency of the future, Electronic Markets, 19 (1).

Novak, J. \& Schmidt, S. 2009. When Joy Matters: The Importance of Hedonic Stimulation in Collocated Collaboration with Large-Displays, Proc. of Interact 2009.

Schwabe, G., Novak, J. \& Aggeler, M. 2008. Designing the Tourist Agency of the Future,Proc. of $21^{\text {st }}$ Bled Conference, Bled, June 2008.

Schwartz, B. (2005). The Paradox of Choice: Why More Is Less, Harperperennial.

Venkatesh, V., Morris, M. G., Davis, G. B. \& Davis, F. D. (2003). User Acceptance of Information Technology: Toward A Unified View, MISQ, 27 (3), pp. 425-478.

Werthner, H. \& Ricci, F. (2004). E-Commerce and Tourism, Comm. of the ACM, 47 (12).

\section{Acknowledgements}

The authors greatly thank Armin Egli for his software technical efforts. The joint project is co-financed by the Swiss federal innovation promotion agency CTI. 